\title{
Urban Innovation Districts as Hotspots for Innovators
}

\author{
Claudia Trillo \\ University of Salford, School of Built Environment \\ C.Trillo2@salford.ac.uk
}

\begin{abstract}
How the space- innovators nexus works in cities? Can this nexus be understood only by looking at location of enterprises and companies or is it necessary to investigate other enabling factors related to the spatial structure of cities? This paper seeks to answer this question by focusing on the mode of using neighbourhood and spaces performed in cities by innovative entrepreneurs. Findings drawn from an extensive dataset built in USA suggest that urban policies should encompass spatial interventions on the built environment, holding the potential to facilitate the construction of a physical ecosystem supportive of innovation. This spatial fabric includes: shared spaces and private small businesses facilitating interaction, both informal and formal, both specialized and multidisciplinary; public services and facilities that allow preserving uniqueness and inclusiveness. Furthermore, the spatial pattern should be supportive of a walkable environment, offering effective transit and public transport facilities. Consistent policy actions include: (1) Launching dedicated programs focused on small target areas, combining spatial planning and innovation-driven economic initiatives; (2) Introducing flexible rules in the funding streams, prioritizing goals over means; (3) Fostering pilot programs including non-conventional beneficiaries and non-traditional eligible costs.
\end{abstract}

Keywords: Innovation Districts, Knowledge-led economic in cities, Spaces for Innovators.

Acknowledgements: The fieldwork conducted in the USA to develop this study was funded by the H2020 Project MAPS LED, grant number 645651.

\section{Introduction}

This paper stems from a trans-disciplinary approach merging economic, social and spatial planning concepts to theorize the role of innovation urban districts as socio-economic physical infrastructures for embedded and sustainable innovation. Combining principles drawn from the New Economic Growth Theory (Romer 1994) and from the socioconstructivist approach to economic growth (Gravenotter 1985) with the New Geography of Innovation emerging from the networked nature of Innovation Districts (Katz \& Wagner 2014), this paper explores the spatial configuration of innovation districts, where knowledge-based growth is occurring, with the aim of unveiling replicable spatial patterns and transferable portfolios of public policies. Whilst a wide body of literature (Katz \& Bradley 2013, Katz \& Wagner 2014, Swinton 2017) suggests that cities should naturally be considered ideal natural clusters, supporting cross-fertilization and innovation thanks to the physical setting they provide for the construction of a collective knowledge, yet a considerable distance persists between regional policies and urban development strategies. This paper suggests that urban policies and economic development policies should be addressed with an integrated approach to mutually reinforce each other. Moreover, whilst innovation is normally considered a positive trigger of local economic development and is usually associated with an increase in competitiveness, a growing body of literature 
suggests that innovation is non-neutral (Florida 2017a, Florida 2017b, Berkes \& Gaetani 2017a, Berkes \& Gaetani 2017b, Walker 2018). It is anticipated that the paper conclusions suggest that inclusive growth (including civic engagement and social equity) should be taken into consideration to ensure equitable innovation-driven local development, thus accomplishing with the intertwined nature of the targets set by the United Nations in the Habitat III agenda. It also anticipated that the key success factors for the development of the Boston innovation ecosystem can be generalized as follows: (1) a quadruple helix model embedded in the physical structure of the two cities (Boston and Cambridge), in which anchor Higher Education (HE) institutions continuously nurture the Entrepreneurial Environment; (2) an entrepreneurial approach emerging from the local governments, eliciting risk taking and bottom up civic participation in tackling key issues in the city: (3) a networking structure of some intermediary actors supporting entrepreneurial collaboration, cross-fertilization and co-creation, which collaborate at multiple-levels thus enabling positive spillovers from the stronger to the weaker contexts; (4) awareness of the socio-economic value of the built environment as enabler of cognitive networks allowing activation of the collective intelligence; (5) creation of civic-led spaces enabling grassroot collaboration and cooperation. This paper is divided in three parts. After having discussed concepts and theories, a robust qualitative dataset based on 30 semi-structured interviews, complemented by direct observations of selected cases is presented, allowing to derive recommendations and lessons to be used in the larger international urban policies- makers arena. Evidence show that there is not a single magic recipe for the successful implementation of place-based and social innovation-driven strategies. On the contrary, the variety of place-grounded combinations of micro and macro initiatives, embedded in the social and spatial fine grain of places and encompassing a diversity of actors, can create the conditions enabling places to thrive and local economic activities to grow in a sustainable way.

\section{Innovation eco-systems and cities. Sustainable innovation and urban development.}

A widespread body of literature suggests that innovation is non-neutral, and that economic segregation is a direct effect of the concentration of knowledge-based industries (Florida 2017a, Florida 2017b, Berkes \& Gaetani 2017a, Berkes \& Gaetani 2017b). The dramatic scenario described in the recent "Pictures of a Gone City" (Walker, 2018) uncovers with a rich dataset the "Dark Side of Prosperity in the San Francisco Bay Area". The unintended negative consequences of a neutral approach to the knowledge economy are mercilessly unveiled, thus demolishing the myth of innovation 'sic et simpliciter'; likewise, blind faith in progress has been dismantled by 20th century human made disasters. However, tackling social inequalities through social services, healthcare, education, affordable housing, appropriately arranged through spatial planning strategies, is still considered a remedial action reflecting a sort of philanthropic attitude rather than a real and proper economic strategy for generating more economic success, perpetuating the outdated dichotomy between neo-liberalism and socialism. Instead, a genuinely place-based approach should allow for the maximizing of the contribution of all regional and local assets, as well as for the contribution (and the benefit) of all the societal assets. This is only apparently in contrast with a regionally focused perspective of development policies: rather than it being an issue of scale of the policies, it is more a matter of how the networked system of actors enables the implementation of regionally sound policies at a fine grain, allowing spillovers and cross-fertilization among stakeholders. The concept of a new geography of innovation and metropolitan revolution (Katz \& Wagner 2014) is based on the recent trend of seeing "a rising number of innovative firms and talented workers ... choosing to congregate and co-locate in compact, amenity-rich enclaves in the cores of central cities." The implications 
of a knowledge-led economy on the formation of wealth have been widely explored in the so-called New Growth Theory, whose central notion is that new knowledge or technology produce increasing returns and do not diminish with use as with other traditional economic inputs. The New Growth Theory intersects the concept of Innovation Districts by demonstrating that, whilst in traditional sectors big anchor companies attract small ancillary companies which depend on the former, in an innovation-driven economic system the link between big anchor companies and small dynamic companies works in two directions in that a big anchor institution attracts small ancillary companies, and small innovative start-ups make the ecosystem attractive for big companies. This is because the cycle of innovation requires a very long pay-off time and even big companies are reluctant to invest in such a scenario. Instead, they prefer acquiring new knowledge and innovation by being located where innovators are. Using a metaphor from nature, life sciences and other highly innovative sectors "want to feed in the waters where the minnows are swimming" (Bluestone \& Clayton-Matthews 2013:8), i.e. the role of big firms is about consuming rather than producing innovation. This theoretical shift is revolutionary in terms of a rationale informing industrial public policies. Whilst big firms do not need public support to thrive, small firms do. "Thus, programs that combine incentives for innovation along with resources to augment human capital should, according to this theory, fuel rapid economic growth more than anything else socially can do to promote prosperity" (Bluestone \& Clayton-Matthews 2013:22), i.e. prioritizing investments on innovators rather than investments on innovation. Here again, the nexus is with urban policies. Where are those innovators located and what role do they play in the production of innovation? Trusheim et al. (2010) suggested a framework for analysing prototypical American Biotechnology Clusters, which allows for relating the success of such clusters with the presence of critical factors. This framework is articulated in three stages through which innovation happens: basic research, translation, and commercialisation. According to this framework, talents (both creators and craftspeople) play different essential roles in all three stages of the innovation process. The nexus between talents and urban environments has been widely explored in the seminal book by Florida (2002) and allows for recognizing the pivotal role played by urban environments in the production of embedded innovation, which is the main conceptual driver of this report. However, after celebrating the creative class (Florida 2002) enthusiastically and linking its blossoming to the renewed importance of city centres, Richard Florida himself admitted that a further nexus exists, between innovation and inequality (Florida 2017a, Florida 2017b). By re-casting the dynamic of innovation- driven urban regeneration into the Sustainable Development Goals agenda set by the United Nations Habitat III conference (UN 2015), and specifically into the Goal 11: Sustainable Cities and Communities, it clearly emerges how policies aimed at boosting innovation need to be framed within a wider and more complex combination of policies supporting a balanced and inclusive socio-economic growth. Combining spatial planning and innovation-driven economic activities has emerged as a potentially successful approach. The interdisciplinary nature of spatial planning allows combining different measures, but most importantly enables effective multi-agents collaboration. A community of innovators enabling a Sustainable Development Goals-oriented innovators' ecosystem encompasses all the different groups constituting the ecosystem itself. The boundary between production and the use of innovation must be blurred to achieve innovation that stems from the collaboration across actors, including local authorities, HE institutions, private companies, start-ups, citizens and communities. The following sections show a possible pathway towards the creation of sustainable innovation urban districts, by drawing inspiration from an extant case study and offering insights to the larger international local policy-makers and spatial planners' community. 


\section{Research methodology}

The research methodology aims at unveiling hidden dynamics in the governance of the innovation- driven urban regeneration and assumes that such knowledge is rooted in the community of innovators embedded knowledge. For this reason, the epistemological stance assumed in this study is interpretivism. The need for appreciating the nexus between spatial organisation of the city and processes triggering and boosting innovation- driven regeneration suggested that the best strategy was a single, in depth case study. This latter has been thoroughly analysed over a 4-years' timeframe, by collecting a variety of data, including secondary non- academic literature (planning documents, research reports, local organisations documents, local newspapers), quasi-ethnographic observation of some selected key- places (including spending working days in such places, taking notes and photos, talking to the people using the places), semi-structured interviews with a robust sample of 30 local experts from academia, local authorities and private companies, participation in meetings and events, multiple fieldwork and direct observations of selected areas. The single case study (the Boston- Cambridge area in Massachusetts, USA), has been initially analysed as unit of analysis, then some selected key- areas have been identified by using the rationale of the innovation districts and thoroughly investigated as focussed sub- case studies. This enormous dataset has been analysed by manually coding photos and texts according to the conceptual framework built by merging the two concepts of innovation districts and embedded growth, seeking to unveil the dynamic underpinned in the processes of urban development of the selected areas. Normally, conventional innovation is mapped by identifying the location of the firms which have obtained a patent. However, embedded innovation often happens "below the radar", sometimes in the form of an ephemeral discussion between innovators. The data gathering methodology reflects the rationale that innovators, not innovation, contain the information regarding the embedded innovation process production. Hence, to identify the critical factors for a successful innovation district and assess these factors' level of readiness, it is essential to map where innovators interact and produce innovation. Innovation hotspots, such as accelerators, incubators and civic engagement spaces, allow for the detecting of the presence of a critical mass of innovators and to locate its space, thus allowing the construction of an assessment framework which includes dense and walkable urban environments, spatially identifiable hotspots, incubators, accelerators, anchor companies and Higher Education institutions, civic innovation centres and socially driven incubators. Flows and interconnections among innovators have been largely investigated by social scientists by approaching this topic from a networking theory perspective, which is not the methodology applied in this study. The space in which innovators produce and use innovation in a virtuous circle, through the cross-fertilization of ideas and knowledge exchange, does have an impact as to whether there are greater or lesser opportunities in terms of achieving interconnected goals (as in the framework introduced by the United Nations with the Sustainable Development Goals, i.e. the United Nations international agenda adopted in 2015 to achieve a sustainable future for all). It is clearly stated that, to be successful, the entire agenda needs to be delivered as a whole, as the different aspects ensuring a sustainable future (equitable development, health environment, etc.) are mutually intertwined and interdependent. The lack of connection between economic process and physical setting prevents managing the interconnections across different spatial scales, actors and factors thus influencing sustainability. Instead, a focus on the spatial fabric of the innovation district allows for the appreciation of the intertwined matters deriving from the innovation-led local development, thus shedding light on positive and negative impacts. The physical setting in which the innovators' ecosystem 
operates is an enabler of embedded innovation because the proximity of innovators, generated by the spatial pattern supporting embedded innovation, fosters cross-fertilization and knowledge exchange across all the different societal actors. Thus, both the main case and the sub-cases have been investigated by reading the socio-economic dynamics through the spatial fabric of the city.

\section{Place-based innovation and innovation districts. Insights from the Boston area.}

Place-based innovation is spatially located in innovation districts, whose urban fabric is supportive of social interaction and whose economic development is framed within a wider planning strategy that allows relating the economic growth objective with the regeneration of a larger regeneration area. The framework represented by "Imagine Boston 2030" is paradigmatic in this sense. This plan is the first comprehensive citywide plan since 1965 and aims at being the framework to preserve and improve Boston. Co-creating and engaging multi-level stakeholders in the planning process has been key. More than 15,000 citizens contributed to the identification of the Boston 2030 goals and generated ideas on how to achieve them. A variety of citizens' engagement tools and instruments have been implemented, including multiple stakeholders (such as industrial partners): open houses (300 participants), visioning kits (330 participants), surveys via text messages $(2,400$ participants), community workshops (270 participants), online/mobile mapping tool (1,070 comments), surveys via street teams (7,090 participants), the Imagine Boston Forum (500 participants), community workshops (180 participants), "Building Blocks" (1,400 participants), Expanding Opportunity feedback (360 comments), the Imagine Boston Week (340 participants), Boston by the Numbers (70 participants), industry roundtables (105), Franklin Park workshop and draft plan survey (185 participants), Forum on the Future (290 participants). The results from this process allowed for the prioritising of equitable issues in the planning decisions such as: housing affordability, equitable transit, creation of job opportunities (City of Boston 2019).
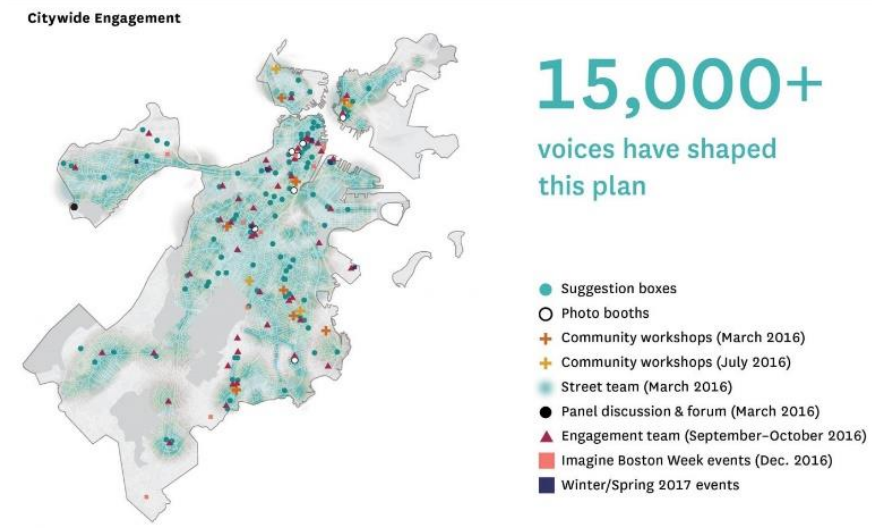

Figure 1. Boston 2030, Citywide engagement. Source: Utile Design, www.utiledesign.com

Likewise, the planning process in the city of Cambridge has also embraced seriously the challenge of co-creating the future decisions shaping the city. Currently, the city of Cambridge has embarked into a comprehensive citywide planning process prioritising the active engagement of multilevel stakeholders. This has been enabled by the implementation of Envision Cambridge, a community-wide process aimed at prioritising urban form and community wellbeing goals through a participatory approach, which has been just finalised in January 2019 (City of Cambridge 2019). As planners in the city of Cambridge have highlighted (interview April 2016), "People who live in Cambridge value diversity", and this attitude has been undoubtedly endorsed by the planning process. 


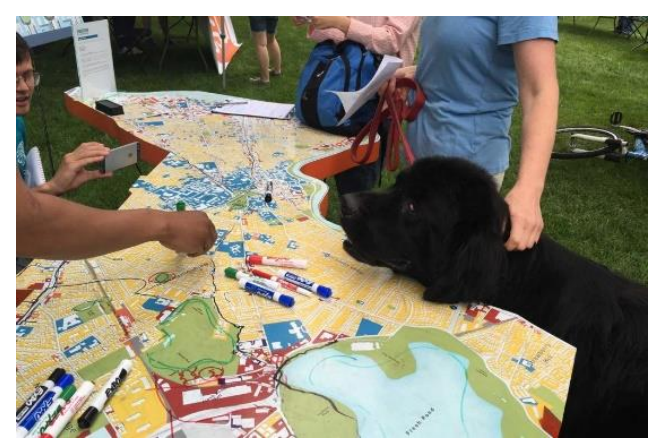

Figure 2. Image: Envision Cambridge. Source: Burohappold Engineering, www.burohappold.com

Alongside the traditional planning process, which demonstrated commitment to co-create through the effective involvement of a wide stakeholders' community, the Boston case evidences also unique experimental attitude. A good example is provided by the Mayor's Office of New Urban Mechanics (MONUM), created in 2010 as one of the initiatives of the Mayor Thomas Menino. Currently, it serves as the City's R\&D Lab and continues its original mission under the leadership of Mayor Walsh; this includes a variety of issues such as civic engagement, racial equity, city infrastructure, and education. Examples of the areas of interest include housing, transport, public spaces, cultural and social resiliency. The peculiarity of MONUM is that, although it is a public office operating in conjunction with the Mayor, it shows the common traits of a typical entrepreneurial actor. Furthermore, MONUM builds partnerships across the quadruple helix. As MONUM experts have pointed out (April 2017), everything is done in partnership with start-ups and universities with the underpinning idea of equating innovation with social goals.

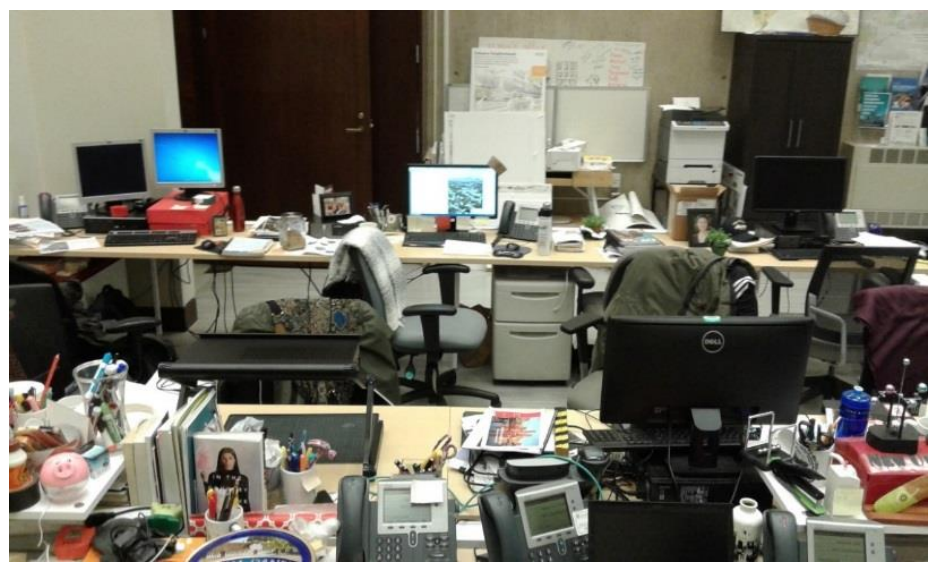

Figure 3. MONUM Office hosts an average of 12 innovators working in close proximity to the Mayor's office. Source: Author's photo

Experimentation and risk taking are two major features of MONUM. It is allowed to take risks that traditional City Departments do not usually take, by developing low-cost, small prototypes that are piloted to test their potential to be scaled up. Examples include: developing a tool to promote savings for college and a career, launching a smartphone app competition that encouraged safer driving by nudging drivers towards better driving habits, offering affordable housing to graduate students while helping older adults stay in their homes by pairing them as roommates. Failures are considered as learning opportunities and are shared across the larger community of public decision makers; successful experiments can be implemented by the traditional departments and scaled up to the city scale. Beside testing innovative ideas, MONUM also plays the role of a "front door" for 
start-ups, universities and residents willing to collaborate with the City. The MONUM process encompasses three phases: exploration of internal and external ideas and projects, experimentation through small pilots, and evaluation of the outcomes to assess whether the project is worth being scaled up (Figure 5).

The Urban Mechanics' start was motivated by the willingness of Thomas Menino to have a governance system that allowed taking advantage of innovation for the community and enabled civic engagement. The Urban Mechanic philosophy is people-centred. One example of successful project is represented by Citizens Connect where people take pictures of what needs to be fixed and send it to the Public Works Department to get them fixed. MONUM developed an app and delivered it to the people; once this happened the Department of Public Works realised it was an extremely powerful tool and took responsibility for it, though it would not have been in the position to take the lead on the prototype. Urban Mechanics is quite a unique experiment and its success is witnessed by the growing interest it is gaining across other cities worldwide. Currently there are mentorship initiatives to develop similar offices.

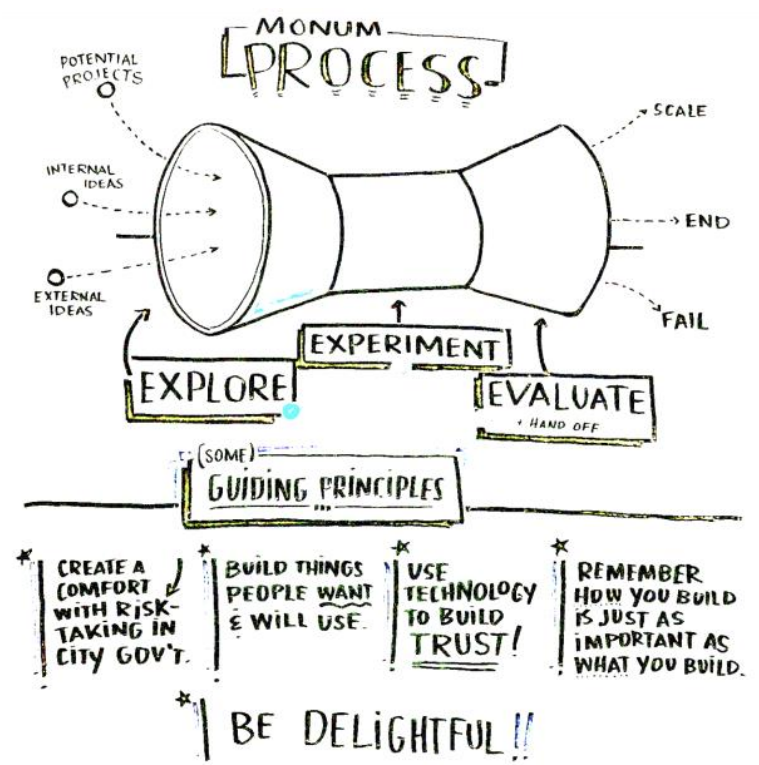

Figure 4. Spurring on innovation in local government Source: Author's photo at contents created by MONUM.

The following section discusses the role played by some of the key-innovators (Masschallenge, CIC and Venture Café) operating in the case study arena (the who), the way they and other players co-create innovation by operating as an intertwined ecosystem (the how) and the urban spaces in which they collaborate (the where). Three cases of Innovation Districts (Kendall Square in the city of Cambridge, Seaport District and Roxbury in the city of Boston) were instrumentally selected to show how innovators and innovation hotspots interact with the urban fabric, demonstrating that urban innovation districts can be enablers of place-based innovation. Coordination and implementation of innovation districts is enabled by complex multilevel governance, including local authorities, (which create favourable conditions through forward- looking and robust spatial planning frameworks) and the state (which not only provides funding and grants, but also contributes to enhancing stakeholders' networking and clustering). Awareness about the importance of cross-collaboration among the different levels emerges from all the stakeholders. Innovation is supported through a variety of instruments but, most importantly, by a consistent rationale, i.e. building on partnerships and collaborations across industry, academia and government. An example of this approach is represented by 
MassTech, the public agency operating in Massachusetts, which supports the innovation economy by recognising the importance of the overall ecosystem efficiency in support of a healthy local economy, rather than the presence of isolated anchor institutions. As a strategic manager at Masstech Collaborative claimed (April 2016), "The ecosystem as a whole is important, having a university is great, but this is just one part of it." The purpose of Masstech is to create and maintain a responsive environment for the development, growth, attraction and retention of technology-intensive and innovation-driven clusters of organizations. This is achieved by enacting a stakeholder-led process, involving so far over 1,347 organizations, 78 higher education institutions, more than 350 Massachusetts' companies and the participation of over 4,300 institutional, civic and entrepreneurial leaders.

\section{Innovation districts as enablers of co-creation and social innovation. Insights from Kendall Square, Seaport, Dudley Square}

Following the Katz and Wagner definition (2014), innovation districts are geographic area where leading-edge anchor institutions and companies cluster and connect with start-ups, business incubators, and accelerators. However, this paper detected another keycomponent of the success of the selected innovation districts with respect to their potential to enable sustainable urban development, i.e. the effective combination of multi-agents strategies made possible by a spatial canvas, dictated by the local governments through spatial patters enabling social interaction and cross- collaboration, i.e., vibrant and walkable urban environments. This characteristic has been identified in the three selected sub- cases, i.e. the innovation districts of Kendall Square, Seaport and Dudley Square. These three sub-cases have been selected with the aim to capture three different ways of interacting across the major players involved in the urban strategy implementation. Kendall Square hosts the Massachusetts Institute of Technology and its development is mainly driven by the strategies pursued by this Higher Education institution. Seaport district has been triggered by a city initiative and has been property led in its following development. Dudley Square reflects a public strategy of regenerating a deprived area and aims at leveraging communities and minorities entrepreneurship dynamics as main driver for change. A relevant and unique element that links together the three innovation districts (and link between them and other organisations) is a non-profit organisation, which enables cross- collaboration and cooperation and facilitates knowledge and even staff exchange. Venture Café is a sister non-profit organisation to Cambridge Innovation Center - CIC (broadly illustrated in the following section), which has the mission of bringing together entrepreneurs, venture capitalists and the greater Boston start-up community. Each Thursday the Venture Café Foundation runs in the CIC an event that gathers together entrepreneurs, investors and advisers, creating a unique opportunity for networking. Both the CIC and the Venture Café operate following a very sophisticated network of connections enabling collaboration across hubs located in very different social contexts. CIC has recently expanded by opening co-working spaces in Miami and Rotterdam and it also interacts with the St. Louis centre, whose context is very different from Kendall Square. However, because of the community of experts managing the centres internationally, the St. Louis centre can benefit from the same high level of expertise offered to the start-ups located in one of the most innovative hubs in the world. Likewise, at a more local scale, the Venture Café Foundation operates the Roxbury Innovation Center (RIC) which is located in one of the most deprived neighbourhoods of Boston. This space hosts programmes supporting local innovators, entrepreneurs and business founders (RIC Monthly Café Nights, Workshop Series) and it offers rental space (meeting and event space to accommodate 4 to 100 attendees) and a Fab Lab. Bringing positive energy and expertise 
to a lower-income and minority population is one of the missions for the Venture Café. Additional to the two locations of the CIC (Kendall Square and Downtown Boston) and the Roxbury Innovation Center, a fourth space, the District Hall, is also managed jointly and is part of the Boston network of spaces for innovators aggregated by the Venture Café Foundation. District Hall is in the heart of the Seaport Innovation District and offers rental space (meeting and event space to accommodate 4 to 400 attendees), an open working space and general facilities hosting a Café night every three months.

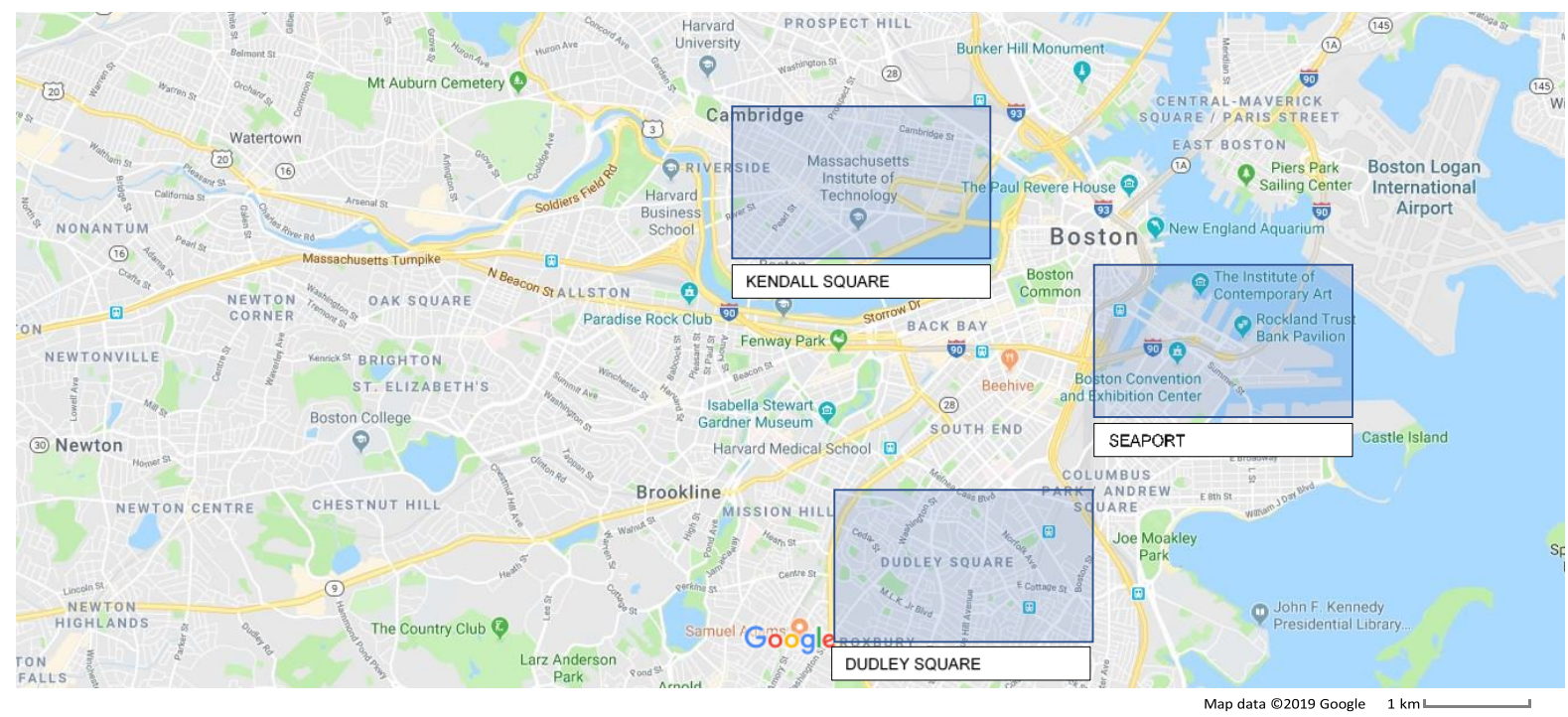

Figure 4: Innovation districts in Boston- Cambridge: Kendall Square, Seaport, Dudley Square (author's elaboration on GoogleMap 2019)

\section{Kendall Square innovation district}

Kendall Square (figures 5 and 6) is located in the City of Cambridge and corresponds to the area where the Massachusetts Institute of Technology sits. It faces the Charles River and relies on an efficient mass transit (the Metro Red Line) that directly connects it to the Boston Downtown. Kendall Square is a former brownfield site, which started in 1868 as an industrial district and consolidated this function with the opening of the first underground line nearby. The presence of the Massachusetts Institute of Technology dates to 1916. Following the Second World War, the area entered an era of decline which the Cambridge Redevelopment Authority (CRA), established in 1955, sought to reverse including through the clearance of 29 acres of land for the accommodation of NASA. Because of a change in the federal government strategies, the plan was not implemented, and the vacant land was partly redirected to the Department of Transportation. A shift in the approach to the redevelopment of the area, managed as a detached industrial estate, happened first with the implementation of the East Cambridge Riverfront Plan, then with the 2001 Citywide Rezoning. 

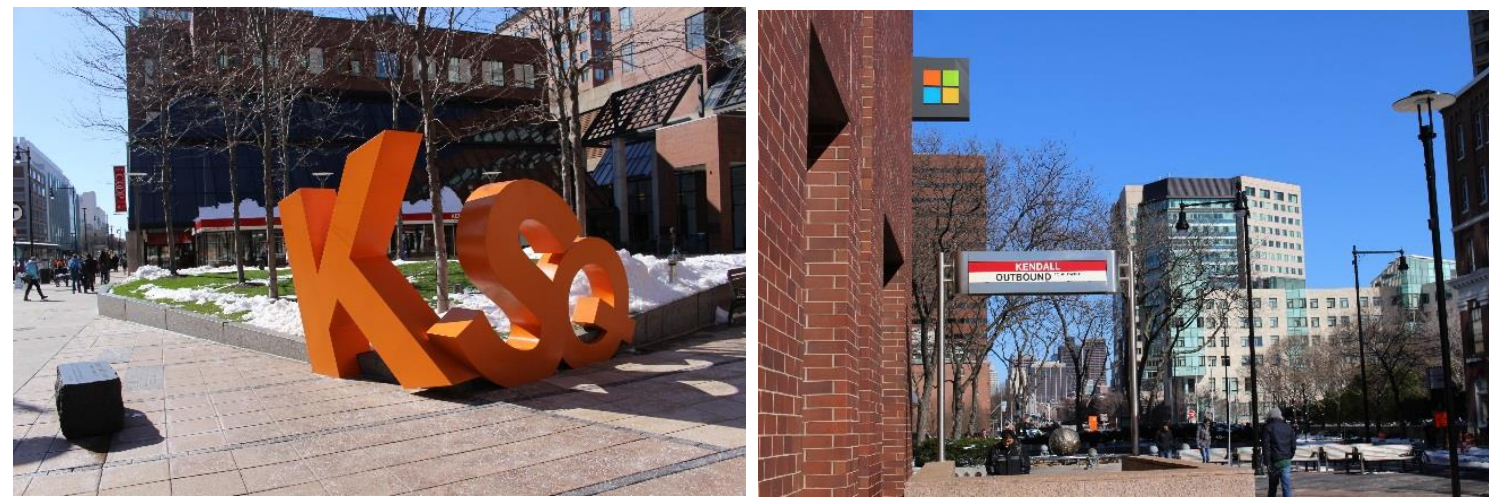

Figures 5-6. Kendall Square (Source: author's photos)

Walkability, quality of open spaces and mixed-use real estate became the norm in the area. Recent massive capital investments confirm the tendency to invest in the area with high quality interventions. The importance of the urban structure as a catalyst for local development is acknowledged both by public and private stakeholders. As can be seen in the current planning documents, the connection between urban fabric and the attractiveness of the area for private companies is evident: "A dynamic public realm connecting diverse choices for living, working, learning, and playing to inspire continued success of Cambridge's sustainable, globally-significant innovation community." Figures 7 and 8 show the mixed use and open spaces fabric in the Kendall Square area.
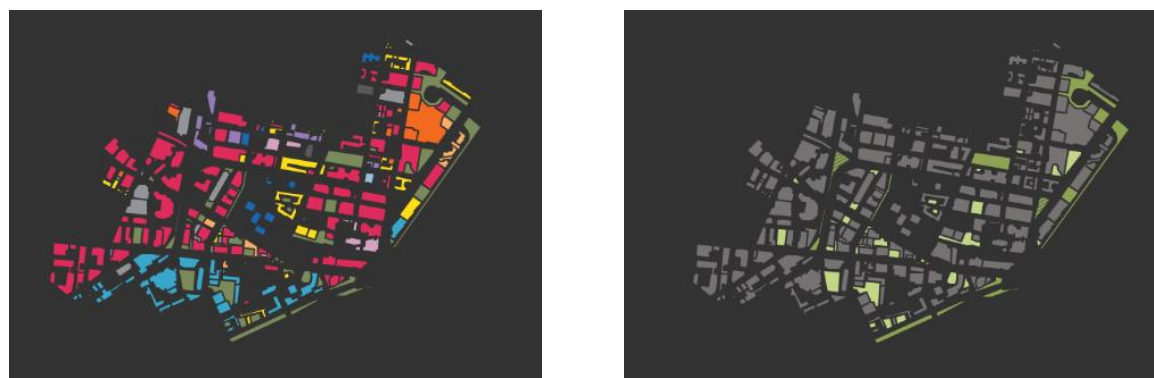

Figures 7-8: Land use and open spaces in the Kendall Square area (author's elaboration on City of Cambridge GIS, 2019)

Recent studies on companies' behaviour in this area proved how the traditional cluster policies (based on subsidizing "anchors" that - once settled down - would attract smaller companies) are now coupled with a bottom-up oriented perspective, in which a significant number of small, dynamic, highly innovative companies create a favourable ecosystem for attracting big companies interested in having interaction with young talent and, possibly, in incorporating smaller (and cheap) companies with a higher potential for growth. Private companies perceive the economic benefit of being localized in an innovative district and are willing to pay the extra costs associated with a more expensive location in order to get extra benefits in return, including the well-being (and related increase in productivity) of their employees and the opportunity to benefit from a powerful network of informal and multi-disciplinary connections, made possible by the specific features of the urban fabric. In addition to the urban pattern encouraging knowledge and innovation building, Kendall Square also includes key-hotspots for informal decision-making and cross-clustering, such as the CIC and related Venture Café activities (Fig. 9-10). 

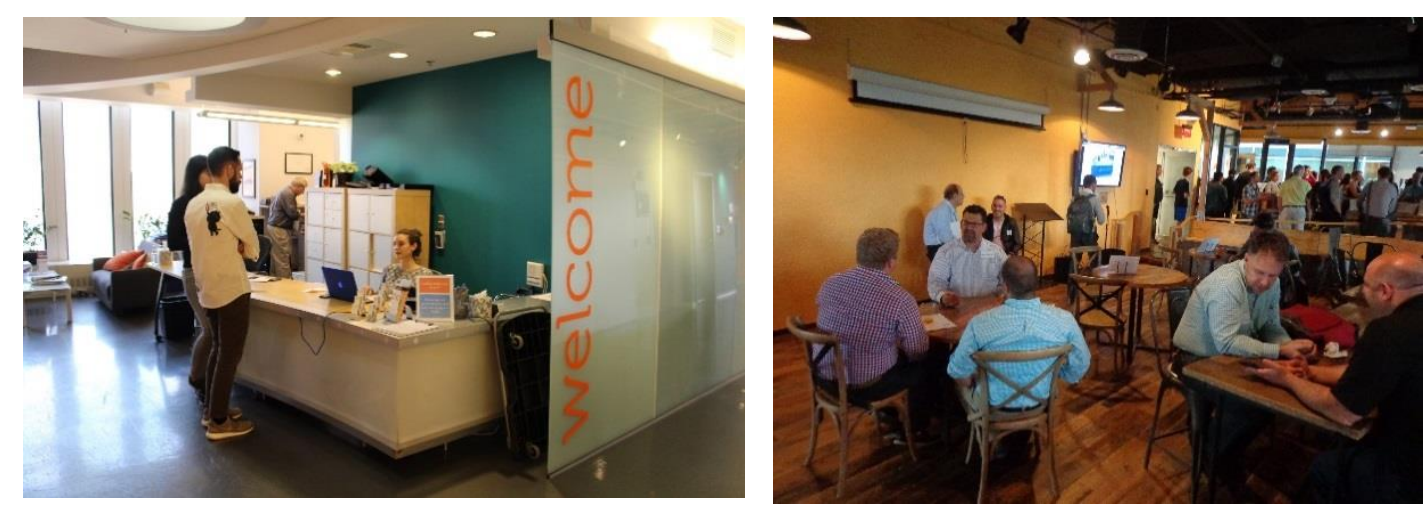

Figures 9 -10. Entrance to the Cambridge Innovation Center. Venture Café, Thursday event.

The Cambridge Innovation Centre (CIC) was founded in 1999 as an incubator. Following an initial flop as an incubator, the CIC was turned into an innovative co-working space. In fact, it is not an incubator nor an accelerator, it is a private entrepreneurial activity based on renting shared and flexible office spaces with an innovative style. It currently hosts over 700 companies across two buildings, located in Kendall Square and in downtown Boston, about 500 of which are start-ups.

In the CIC (based in Kendall Square, Cambridge), flexible and high-quality spaces are offered for a reasonable cost, since prices range from US $\$ 425$ to US $\$ 1,500 /$ person/month all included (stocked kitchens, conference rooms, Internet, printing \& copying, telephones, high-end furniture, operational \& technical support and concierge). Cross-fertilization of innovative ideas is considered the major asset offered to the hosted companies that are mixed across the floors and not clustered by sector. Informal interviews with local stakeholders have confirmed the extraordinary role played by the CIC in building a favourable physical ecosystem, spurring on innovation and supporting start-ups' creation. Additionally, the CIC have allowed some large companies, such as Google, to temporarily settle down in Kendall Square prior to making the final decision of moving there with the entire headquarters.

\section{Seaport Innovation District}

The Seaport Innovation District is a 1,000 acre area located South of the Financial District and Boston Downtown on the former industrial port. It was launched in January 2010 by the former Mayor Menino, with the deliberate intention to bring together entrepreneurs in a target area assuming that proximity and density would have acted as booster for innovation and co-creation. The spatial strategy was based on mixed use, including office, industrial, research, convention, and housing. The Innovation District was intended to participate in the wider industrial strategy for the Greater Boston's innovation economy, which had already included Kendall Square and other areas. The Innovation District has attracted businesses and created over 5,000 jobs through aggressive recruitment and support, which allowed bringing to the area industrial giants such as Vertex Pharmaceuticals or the Fraunhofer Center for Sustainable Energy. In 2011, Babson College moved relevant activities to the area. Large development projects added to the area new opportunities for innovative co-living (such as Factory 63) and co-working, including accelerators (such as Masschallenge). The original vision of the district was based on four main features: (1) Industry- agnostic. The philosophy was to avoid prioritising the growth of a single industry, being instead open to industries of every kind. (2) Clusters. Proximity and density were the spatial features enabling knowledge sharing and co-creation, captured in the motto "Work, Live, Play". (3) Experimental. The plan was expressed in form of 
vision rather than rigid set or rules, enabling flexibility and adaptation. (4) The City as Host. Rather than a University or research firm, the city stood out to take the role of anchor institution. A milestone in the development of the seaport district public spaces fabric has been the construction of the District Hall, as the product of a cross-sector partnership aimed at creating a facility serving as a sort of living room for the community and local entrepreneurs. Technically the District Hall is a Community Benefit stemming from an agreement between the city and the developer, thus its construction has been at no cost for the city. The City of Boston provided a tax agreement according to which the restaurant located in the building is the only entity in District Hall paying property taxes in relation to its commercial activity, while the rest of the space, operated by the Venture Café, is taxexempt. The District Hall offers a range of different opportunities. The main co-working space is entirely free of charge and can be used by anyone entering the building. If offers free Wi-Fi- connection and working desks usable on a first arrived- first served basis. The District Hall includes meeting rooms of different sizes, bookable at reasonable rent. However, socially- engaged organisation may be offered the spaces for free. In 2018, District Hall hosted over 900 events and over 95,000 visitors, and invested 1 million in the community in sponsored event spaces.

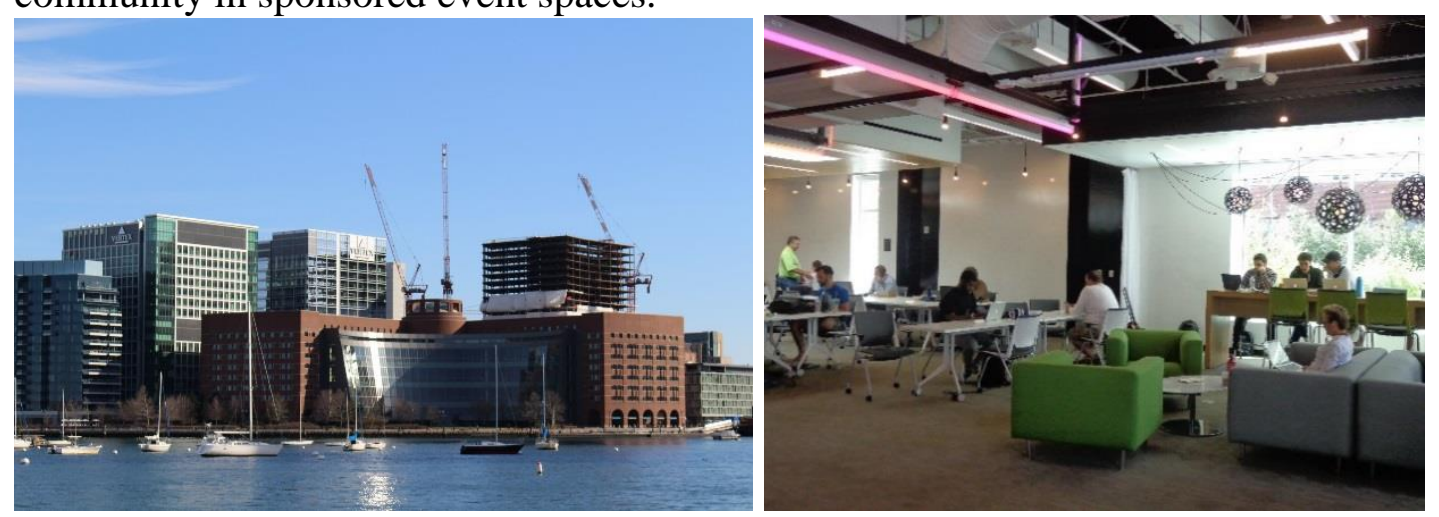

Figures 11-12. Seaport District and District Hall Source: Author's photos

Another milestone in rising the profile of the Searport District as an attractive place for entrepreneurs and innovators has been the choice of Masschallenge to locate its headquarters in the heart of the district in a former large-scale industrial building. Masschallenge is an industry-agnostic (i.e. no industrial sector is prioritised over others) non-profit accelerator created in 2010 with the intent to support producing entrepreneurs. Part of the building was given for free to Masschallenge thanks to the support of the City who negotiated with the developer. The advantage of this for the developer has been that the presence of Masschallenge in the building allowed for a doubling its real estate value since it also secured the relocation of big companies such as Autodesk. Because of its role in anchoring the relocation of relevant companies, Masschallenge has significantly contributed to the regeneration of the Seaport District area. It is managed by a publicprivate partnership financed by three kinds of actors: corporations, foundations and government (these latter two institutions mainly use Masschallenge for renewing built spaces or exploring opportunities).

Each year Masschallenge admits hundreds of finalists to its accelerator programmes. The most promising are awarded cash prizes at the end of the programme. It has accelerated over 1,000 start-ups so far. Following the success of the Boston accelerator, Masschallenge has expanded by opening programmes in other countries (Mexico, Israel, Switzerland, UK) through a franchise model (Figure 6). The four key ingredients which make a place suitable to host a Masschallenge are: strong educational institutions, strong governmental support, potential for funding partners such as big companies or foundations, and the presence of 
start-ups. Within the Boston ecosystem, Masschallenge networks with other incubators and accelerators, such as Greentown Labs and Pulse. As managers at Masschallenge have pointed out (March 2017), they are extremely collaborative with public key stakeholders who join key meetings. Furthermore, they actively network with other incubators and accelerators, even including in their newsletters other institutions' news and sending to other incubators and accelerators companies that are suitable to be hosted in more specialised environments.
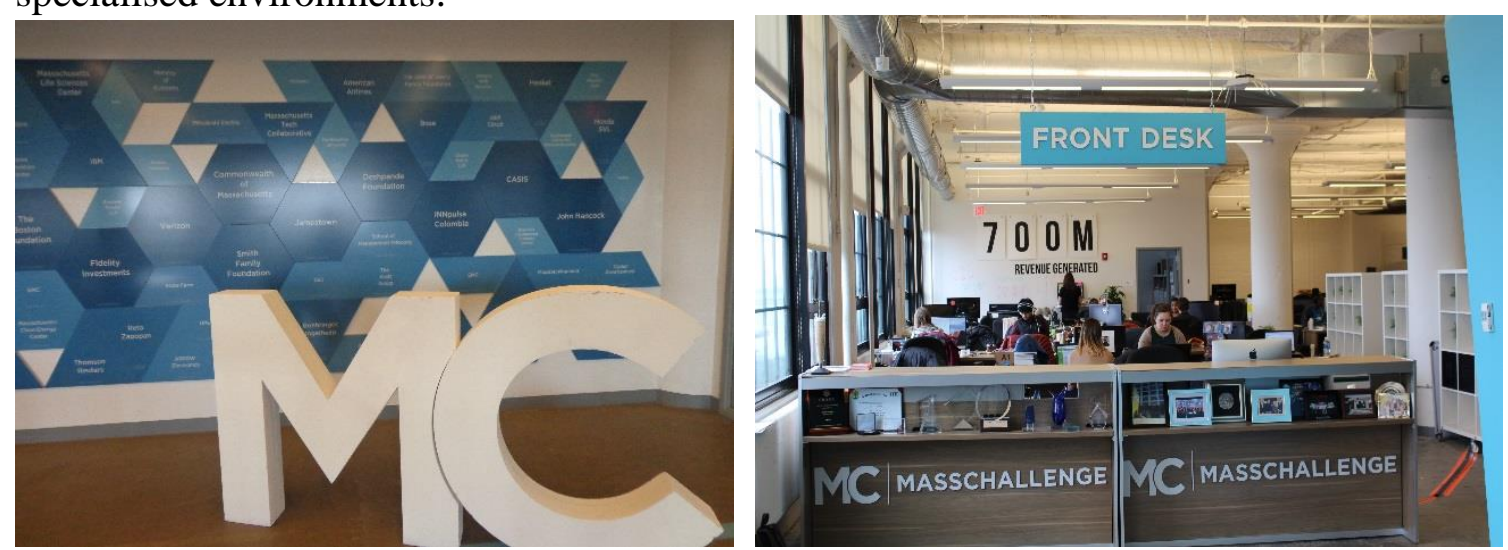

Figures 13 - 14. Masschallenge entrance to the co-working space. Source: Author's photo.

\section{Dudley Square Innovation District}

Dudley square represents the heart of Roxbury, a historically deprived area of the City of Boston. Thanks to two main key- investments, the construction of a mass transit hub and connection (the Silver Line Bus Rapid Transit and Dudley Square new station) and the transformation of the Bruce C. Bolling Municipal Building into an innovation center (the Roxbury Innovation Center), the square is acting as catalyst for the regeneration of the wider neighbourhood. The Dudley Square Vision Project was launched by the former Mayor Menino in 2007 and included three key- elements: (1) real estate development encouraged by the refurbishment of an anchor public building; (2) programmatic development to create a thriving commercial district; and (3) community engagement.

The Roxbury Innovation Center is a major anchor in the Dudley square regeneration process. It is located in a reused and publicly funded 3,350square foot building and offers a variety of services in line with the higher standard incubators, including business support, training, spaces for meeting and co-working, a Fab Lab. The companies launched by the Roxbury Innovation Center are usually led by minorities and firmly rooted in the neighbourhood community.
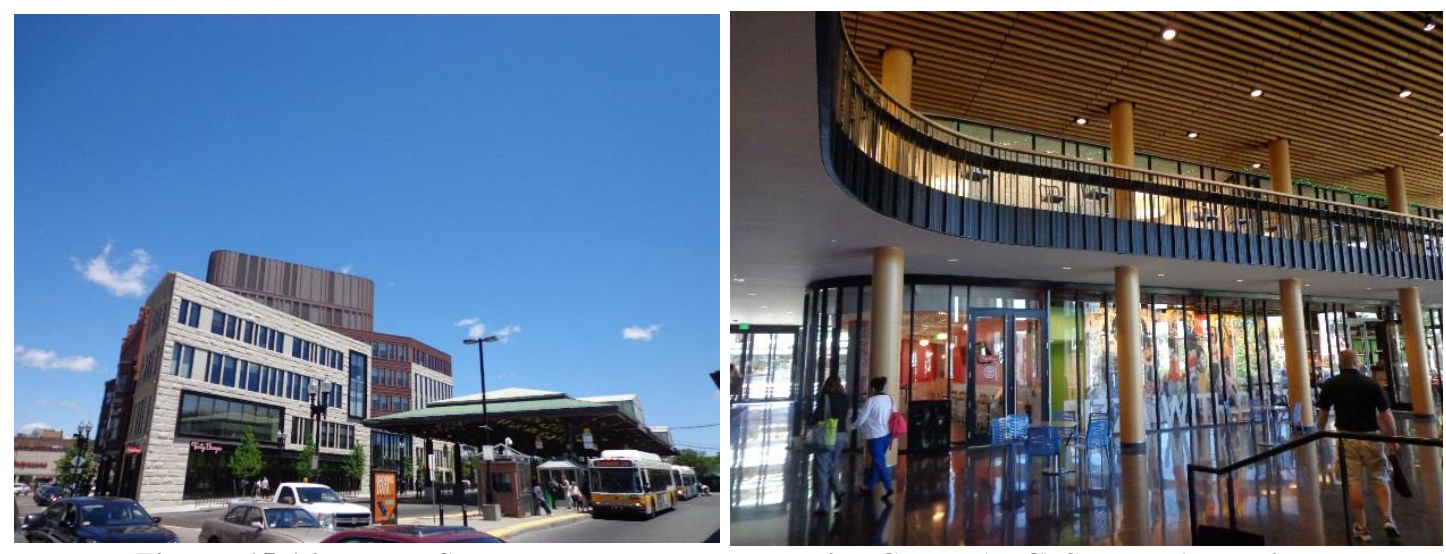

Figures 15-16. Dudley Square and Roxbury Innovation Center (RIC) Source: Author's photos 


\section{Discussion and conclusions}

At the local level, all the examples explored in this report stem from a robust and forwardlooking local strategy, envisioned by local governments and supported by anchor academic and industrial institutions, enabled by funding streams from both private and public actors, enacted by a variety of academic, private and public actors, and complemented by civic engagement.

The Kendall Square District was kick-started by a public-driven redevelopment plan, enhancing the MIT anchor institution. Today, the entrepreneurial ecosystem has evolved in one of the most competitive networks on the planet, including all scales of companies, from technology and pharmaceutical giants to one-person start-ups. One example of how the local entrepreneurial community has deliberately taken leadership of the vision shaping the Kendall Square future is represented by the creation of the Kendall Square Association (KSA). In 2008 a group of Kendall leaders decided to start an initiative aimed at connecting and exchanging ideas at street level, holding the mission to build partnerships and advocate for public policy issues. With over 180 members, KSA provides a platform for collaboration on projects of common interest. The Learning Communities cover issues such as diversity and inclusion crises, equitable transport, eco-districts, and showing engagement with wider societal issues.

The Seaport District stemmed from a vision of the Boston Mayor and its success was achieved through a combination of public (state and federal) and private (Masschallenge) investments. The relocation of the Babson college into the Financial District, in close proximity to the bridge connecting the downtown with the Seaport area, completed the quadruple-helix model in the area (Baily and Montalbano 2018; Intersector Project 2015). The innovation district was made possible by one of the most important infrastructural projects in the history of US cities, the Big Dig. The elevated Central Artery that was cut of the waterfront from the Boston downtown was channelled into a tunnel, thanks to massive federal funds, thus enabling the connection between Seaport and the Financial District. Further funds invested in the infrastructural transit system allowed for the completion of the Silver Line, the Bus Rapid Transit connecting the Seaport District to the Airport. Supported by these massive public capital investments, the area was then targeted by both public and private initiatives, creating the conditions for attracting business and private investments. The entrepreneurial ecosystem was created thanks to a combination of tax credits (which brought Vertex to the area) and private support (through the biannual call for start-ups issued by the Masschallenge).

The Dudley Square local plan is focused on improving connectivity through the creation of a key- transit station served by the new Bus Rapid Transit line, complemented by the launch of the Roxbury Innovation Centre near to the new transit station (hence, two major public capital investments). The latter has been deliberately built to bring innovation and entrepreneurship to an area traditionally neglected by investments and business and, indeed, it is serving as an anchor for building trust across the entrepreneurial community. A former MIT graduate, Gilad Rosenzweig, founded the start-ups' accelerator 'Smarter in the City' near Dudley Square, which launches 2 cohorts of 5 start-ups per year. The presence of the Roxbury Innovation Center, which is managed by the Venture Café (the same non-profit operation at the Cambridge Innovation Centre in Kendall Square), in combination with the Smarter in the City accelerator, are changing the perception of the area which is now targeted by venture angels and funders. As the Smarter in the City founder stated (April 2017), it is still difficult to say whether the accelerator induced a shift in the pride of the locals, nevertheless, there was an assumption that people from that neighbourhood were unable to have ideas and now this is no longer true. 
The three cases show how the coordination of multilevel stakeholders was mainly steered by local authorities (i.e. the City of Boston and the City of Cambridge), but was firmly backed by both federal and state funds and programmes. Local authorities have acted as main orchestrators; nevertheless, state and federal governments have supported their strategic visions with consistent actions. The state of Massachusetts provided support through an agency, Masstech, which was deliberately conceived to enable co-creation rather than to deploy bottom-up strategies or preconceived plans and projects. The multiagents' arena, including anchors (such as higher education institutions and big companies) and small actors (such as innovators from academia and industry and industrial leaders) collaborated proactively to deploy co-created strategies in the target areas, i.e., the innovation districts.

Drawing from the empirical data, in the Boston-Cambridge area it is possible to identify at least three enabling factors for sustainable innovation districts: the spatial ecosystem for innovation hotspots, the location of innovators, the multi-level nature of innovation.

The spatial ecosystem for innovation hotspots

Innovation hotspots work better in walkable environments and in socially and physically dense neighbourhoods. In all the locations that were investigated, physical and spatial planning supported the densification of the area by increasing the public transport and encouraging mixed-use. Evidence has shown that these kinds of urban ecosystems tend to be more attractive for innovators. This happens because social innovators tend to prefer socially interesting environments, hence, dense and high-quality urban settings.

The location of innovators

The presence and diffusion of innovative subjects are spread across different categories of stakeholders. Sophisticated governance allows for a blended public private approach, encompassing civic organisations, second tier NGOs, collaborating through structured frameworks thus allowing space for risk taking even in those sectors which are usually risk-adverse. A good example of this approach is represented by UrbanMechanics, a task force operating in close conjunction with the city of Boston Mayor, allowing for experimentation and the testing of initiatives with the aim of upscaling only those that demonstrate that they can be successful.

The multi-level nature of innovation

Economic-financial, technological, social, institutional and even spatial innovation is activated by networking on multiple scales. Networking works both horizontally and vertically, creating local-local and local-international linkages that activate the circulation of knowledge and generate spillovers far beyond the border of the Boston metropolitan area. Such spillovers promote equity by binding in either neighbourhoods in the same city or even cities which are outside the Boston metropolitan area, the State of Massachusetts and the whole country (hence cities worldwide) that are lagging behind thus allowing a consistent level of highly specialised expertise across a variety of different geographic contexts. A significant example is the Venture Café network, linking together two Innovation Centres in competitive neighbourhoods (the Cambridge and the Downtown Boston ones) with an Innovation Centre triggering the economic revitalisation of a formerly deprived and blighted area (Roxbury). It also networks with other US cities (e.g. St. Louis) and European cities (Rotterdam). However, evidence of a correlation between this mechanism and the parallel process of local urban regeneration is still far from being proved.

A major challenge to effective embedded development is that urban policies and placebased innovation are still poorly interconnected, challenged by a silo-approach plaguing all the scales and by the difficulties in achieving genuine collaboration from all the keyplayers. However, the alignment between urban policies / spatial planning at the district 
scale and place-based innovation initiatives is the cornerstone of the success of the case study discussed in this report. Possible examples are:

the mutual benefit from having the Masschallenge accelerator within the Seaport Innovation District, this latter enabling the relocation of a wide range of small, medium and large companies (e.g., Vertex; PWC, GE) in a concentrated area;

the positive dynamics created by the District Hall and the Seaport District, the former playing the role of both socially-oriented co-working space and civic centre, the latter in need of a civic hub for maximising the social spillovers of the development of the area; the complex role played by the city of Boston, showing an understanding of the importance of spatial planning to support a consistent framework of economic and regeneration initiatives (e.g., the new Plan 'Boston 2030') and civic engagement.

The urban linkage allows for the tackling of the issue of the inequalities generated by the innovation ecosystem, e.g. by: steering the creation of a balanced provision for public spaces, offering opportunity for engaging citizens and leveraging civic values; monitoring the pursuance of the Sustainable Development Goals in a consistent manner, made possible by the simultaneous vision offered by the spatial canvas supporting different development strands; maximising the interaction between accessibility, equity and competitive advantage, through the correct implementation of transportation plans consistent with the major areas of job opportunities and housing.

Thanks to the canvas represented by the urban fabric, all those dynamics happen in a concentrated place, thus mutually reinforcing. On the other hand, it is the urban and neighbourhood scale which allows the appreciation and steering of the innovation-led local development within the framework of the Sustainable Development Goals, because these latter become explicit at the local scale (rather than at the regional scale).

Drawing from these considerations, some policy recommendations are formulated below. The construction of a physical ecosystem supportive of innovation should be deliberately supported. These spaces include shared spaces and private small businesses facilitating interaction, both informal and formal, both specialized and multi-disciplinary; public services and facilities that allow the preservation of uniqueness and inclusiveness. Furthermore, the spatial pattern should be supportive of a walkable environment, offering effective transit and public transport facilities. The economic benefit for the private companies located in such areas is proved by the empirical findings from the case study, although not yet quantified. Launching dedicated programmes focused on small target areas combining spatial planning and innovation-driven economic initiatives (and funds) and monitoring them against the targets of the Sustainable Development Goals could be a possible vehicle for deploying sustainable innovation districts.

Secondly, social innovators should be identified as key-players for testing small scale and pilot actions, locally embedded and grounded within the entrepreneurial ecosystem. As demonstrated by the experimental approach of Urban Mechanics, entrepreneurial discovery and risk taking are not in conflict with reliability in the use of public funds, as long as a reasonable cap in the expenses is established. Moreover, both public and private mediators can manage the creation of entrepreneurial hotspots, as demonstrated by the Masschallenge example. This could be achieved by fostering pilot programmes (including non-conventional beneficiaries and non-traditional eligible costs) and allowing below-theradar and social innovators to grow.

\section{References}

Aautio E., Kenney M., Mustar P., Siegel D. and Wright M. (2018) 'Entrepreneurial innovation: The importance of context', Research Policy, Vol. 43, Iss. 7 (Sept. 2014), pp. 1097-1108 
Berkes E., Gaetani R. (2017a) Income segregation and rise of the knowledge economy. https:// sites.northwestern.edu/. Accessed 13 Dec 2017

Berkes, E., Gaetani, R. (2017b) The geography of unconventional innovation. https:// economicdynamics.org/meetpapers/2015/paper_896.pdf. Accessed 6 Dec 2017

Bluestone B., Clayton-Matthews A. (2013) Life Science Innovation as a Catalyst for Economic Development: The Role of the Massachusetts Life Science Center, The Kitty and Michael Dukakis Center for Urban and Regional Policy, Northeastern University.

Baily N., Montalbano N. (2018) Clusters and Innovation Districts: Lessons from the United States Experience. The Brookings Institution, January 2018. Available at: https://www.brookings.edu

City of Boston (2019) Imagine Boston 2030. Plan Overview. Available at: https://www.boston.gov/departments/mayors-office/imagine-boston-2030

City of Cambridge (2019) Comprehensive Planning. Envision Cambridge. Available at: https://envisioncambridge.consider.it

EC (2013) EU: Guide to Social Innovation. http://s3platform.jrc.ec.europa.eu/documents/20182/84453/Guide_to_Social_Innovation. pdf. Accessed 10 March 2019

EC (2011) RIS3 Guide, Joint Research Center, Smart Specialisation Platform Available at: http://s3platform.jrc.ec.europa.eu

Florida R. (2002) The Rise of the Creative Class. And How It's Transforming Work, Leisure and Everyday Life. NY: Basic Books

Florida R. (2017 a) How Innovation Leads to Economic Segregation. CityLab, 24th October 2017. Available at: https://www.citylab.com/life/2017/08/the-geography-ofinnovation $/ 530349$

Florida R. (2017 b) The Geography of Innovation. CityLab, 3rd August 2017. Available at: https://www.citylab.com/life/2017/08/the-geography-of-innovation/530349

Gravenotter M. (1985) Economic action and social structure: the problem of embeddedness. 32 American Journal of Sociology, 91, 1985. pp. 481-510

Intersector Project (The) (2015) The Development of Boston's Innovation District: A Case Study of Cross-Sector Collaboration and Public Entrepreneurship. http://intersector.com/wp-content/uploads/2015/10/The-Development-of-Bostons-

Innovation-District.pdf . Accessed 10 March 2019.

Katz B., Bradley J. (2013) The Metropolitan Revolution: How Cities and Metros Are Fixing Our Broken Politics and Fragile Economy. Brookings Institution Press, Washington D.C.

Katz B., Wagner J. (2014) The Rise of Innovation Districts: A New Geography of Innovation in America. Brookings Institution Press, Washington D.C.

Monardo B., Trillo C. (2016) Innovation strategies and cities. Insights from the Boston Area. In: Urbanistica. N. 157, pp. 151-155

Neely J. (2018) Boston Startups Guide. Available at: https://bostonstartupsguide.com/

Romer P. (1994) "The Origin of Endogenous Growth", Journal of Economic Perspectives, Vol. 8, n. 1, pp. 3-22

Swinney P. (2017) How do we encourage innovation through clusters? In: Center for Cities. Available at: http://www.centreforcities.org

Trillo C. (2018) The Rise of the Co-creative Class: Sustainable Innovation-Led Urban Regeneration. In: F. Calabrò et al. (Eds.): ISHT 2018, SIST 100, pp. 411-421

Trillo C. (2016) Smart specialisation strategies as drivers for (Smart) sustainable urban development. In: Ergen, M. (ed.) Sustainable Urbanization. InTech. https://www.intechopen.com/. Accessed 06 May 2016 
Trillo C. (2017) Towards an assessment methodology for smart specialisation strategies: sustainable local development. In: IRWAS, vol. 149. University of Salford (2017)

Trusheim M., Berndt E., Murray F., Stern S. (2010) “American Entrepreneurial Chaos or Collaborative Industrial Policy: The Emergence of the Massachusetts Biotechnology Super-Cluster", Contributed Paper for the $2^{\text {nd }}$ Conference on Corporate R\&D (European Commission, 2010)

UN (2015) About the Sustainable Development Goals, Available at: https://www.un.org/sustainabledevelopment/sustainable-development-goals

US Chamber of Commerce Foundation (2016) Innovation that matters. Available at: https://www.uschamberfoundation.org/innovation-that-matters

Walker R. (2018) Picture of a Gone City. Tech and the Dark Side of Prosperity in the San Francisco Bay Area. Oakland, CA: PM Press

Zimmermann C. (2015) 7 Up-and-Coming coworking spaces in Boston. Available at: https://www.americaninno.com/boston/7-up-and-coming-coworking-spaces-in-boston 